\title{
Signaling task awareness in think-aloud protocols from students selecting relevant information from text
}

\author{
Gonny L. M. Schellings • Hein Broekkamp
}

Received: 9 July 2009 / Accepted: 28 December 2010 /

Published online: 20 January 2011

(C) The Author(s) 2011. This article is published with open access at Springerlink.com

\begin{abstract}
Self-regulated learning has been described as an adaptive process: students adapt their learning strategies for attaining different learning goals. In order to be adaptive, students must have a clear notion of what the task requirements consist of. Both trace data and questionnaire data indicate that students adapt study strategies in limited ways and that their awareness of task demands seems to be low. In the present think-aloud study we examined task awareness of tenth-graders who selected text fragments in three different selection tasks. Students' task awareness was analysed at a global and a local task level. Awareness at the global task level refers to processing the instruction and reflecting about general selection goals; awareness at the local task level includes spontaneous reasoning about selecting specific text fragments. On either level, students showed difficulties in verbalizing task demands. In line with previous work, tenth-graders apparently experience a limited awareness of task demands.
\end{abstract}

Keywords Task awareness · Text studying · Thinking aloud

Theories about metacognition and self-regulated learning stress the need for students to adapt their learning strategies to demands of a task in order to optimize their learning performances (Boekaerts and Corno 2005; Butler and Winne 1995; Pintrich et al. 2000). Theories about reading and text studying imply the construction of the meaning of texts, but learning from text goes beyond meaning construction as the learner has to acquire the presented information in such a way that a criterion task can be performed (e.g., Anderson and Armbruster 1984). Text studying could be defined as a goal-directed type of reading by which the readers prepare themselves for a future performance or state. For example, students may prepare themselves for taking a test or they want to learn more about a

G. L. M. Schellings $(\bowtie) \cdot H$. Broekkamp

Research Institute of Child Development and Education, University of Amsterdam, Spinozastraat 55, 1018 HJ Amsterdam, The Netherlands

e-mail: g.1.m.schellings@uva.nl

H. Broekkamp

e-mail: h.broekkamp@uva.nl 
particular topic that they consider interesting. In order to increase their study performance, students may attempt to adapt their text studying strategies towards the goals they pursue.

Attuning to task demands does not occur as a matter of course; self-regulation seems to be necessary (Butler and Winne 1995). Self-regulated learning starts with some kind of task orientation, and during task execution students should keep task demands in mind (cf. Winne and Hadwin 1998). In reading research, task effects or effects of reader's perspective taking have been documented (cf. Alexander and Jetton 1996; Bråten and Samuelstuen 2004; Schraw et al. 1993). For example, in the study of Schraw et al., information which was relevant for perspective taking (i.e, burglar perspective versus home-buyer perspective) was recalled well irrespective of the structural importance of the information in the text. Bråten and Samuelstuen showed that reading purpose (i.e., debating about text content versus test taking) influenced through previous knowledge the self-reported use of memorization and elaboration strategies in text processing. Several studies indicate that adaptive studying increases students' performance, when the criteria by which performance is assessed, correspond to the imposed goals the students have pursued (cf. review of Anderson and Armbruster 1984, or review of Reynolds 1992). In their review Broekkamp and Van Hout-Wolters (2007) noted that many studies have yielded inconsistent results, which might be explained by the different research methods that were used to assess students' strategy adaptation. For example to assess students' adaptation, many studies rely on student performance on the criterion tasks (e.g., test scores) and do not assess the process of studying itself. Moreover, when studies did examine the process of studying, they relied upon retrospective data (e.g., interviews and questionnaires) or product data (traces). This think-aloud study adds a different research method for assessing students' adaptation of studying by focusing on a first step in student's adaptation. Adaptive studying requires the students to be aware of the specific demands of the particular task. For this reason, we examine to what degree students are aware of task goals when asked to select text parts in line with these goals. This process-oriented study aims at providing insight in the task attuning activities of students and in the instruction that promotes task orientation.

\section{Theoretical framework}

Self-regulated learning: being aware of task demands Regulatory skills refer to activities that help control one's thinking or learning. Although a number of regulatory skills have been described in the literature, all these skills still fit the original Flavell's three-fold categorisation in metacognitive skills: planning, monitoring, and evaluation. According to Schraw and Moshman (1995) planning involves the selection of appropriate strategies and the allocation of resources that affect performance (for example making predictions before reading, strategy sequencing and allocating time or attention before beginning a task). Experienced learners possess metacognitive knowledge and use that knowledge to regulate learning before they undertake a task. Some authors differentiate between planning and orientation (cf. Meijer et al. 2006). Orientation activities concern goal setting, activating prior knowledge, predicting content before reading, skimming (sub)headings before reading, and establishing task demands. Orientation activities actually precede planning activities, which refer to formulating an action plan and subgoaling.

In her description of self-regulated learning, Butler (1998b) focuses on task-analysis and interpreting task requirements (task interpretation). She emphasises that successful task interpretation is foundational to focused engagement in tasks and ultimately success in school. During task interpretation, students decipher the requirements of a given task and 
hence should be aware of the task demands. Then, students self-regulate all further learning activities based on their interpretation of task demands (Butler and Cartier 2004; Butler and Winne 1995). Task interpretation is a joint function of students' metacognitive knowledge about tasks, their conceptions about the nature of academic work, and how well students actively and strategically focus attention on deciphering task demands. Successful task interpretation itself requires a number of reflective and strategic activities. These activities include actively searching for clues that might reveal task demands, interpreting oral or written instructions to decipher expectations, accessing and evaluating the applicability of previously constructed metacognitive task knowledge, thinking about a particular teacher's usual expectations, and integrating these sources of information to derive criteria for planning, directing, and evaluating performance. The demands of a particular task are implied by different task factors, as well, such as task instructions, type of task, subject areas, and media (Winne and Hadwin 1998). This present study aims at deciphering the task demands of three different selection tasks in text studying.

Learning from texts: selecting relevant information Selection of relevant information is the first and requisite step to build a macrostructure of the text in comprehending texts (cf. Van Dijk and Kintsch 1983; Kintsch 1998) and the first and requisite step in meaningful learning: students construct knowledge by selecting relevant information and interpreting it through one's existing knowledge (cf. Mayer 1992). Theoretical models of selective attention in text studying assume that students increase their attention for relevant text elements at the cost of their attention for less relevant text elements. Early selective attention models focused on the students' ability to increase their attention to more important textual units at the expense of attention to less important textual units (e.g., Anderson 1982). Later models also include students' ability to formulate criteria for determining the relevance of textual units (Hidi 1995; Reynolds 1992). For example, students may use three kinds of criteria to determine the relevance of textual units: authorbased, instruction-base, and reader-determined (Alexander and Jetton 1996; Van HoutWolters 1990).

By all means, selecting information from text remains important. Even in modern times in which learning from multimedia and applying new technologies is apparent in everyday school learning, learning still heavily depends on processing and learning from verbal information. Since students have access to many different text documents (multiple documents) or different information sources (internet), selecting relevant information seems becoming even more important (cf. Cerdan and Vidal-Abarca 2008; Walraven 2008). The need to search for specific information is ubiquitous in school, community, and occupational contexts. Furthermore, locating information in texts, manuals, and other documents consumes the vast majority of occupational reading time among adults (Guthrie and Kirsch 1987).

In educational settings, texts are used to reach instructional objectives. Students are most often expected to comply with the particular reading and study tasks imposed by the educational system (mostly tests constructed by their teachers). Study tasks involve both external and internal characteristics. External task characteristics include task demands or study goals determined by others than the learner. Internal task characteristics include personal goals the students formulate in relation to the task. These personal goals may emerge from students' deep-seated interest in the domain under study, students' orientation towards superior academic performance or a tendency to limit academic efforts in order to protect their well-being (Alexander and Jetton 2000; Boekaerts and Corno 2005). Task demands and personal study goals may coincide, for instance when the students' interest is 
caught or met by the content that they are required to study (Hodgson 1997; Schraw et al. 2001). However, some degree of internalization of task demands is necessary for students, in order to be able to adapt to task demands at all (Butler and Winne 1995; De Corte 1996).

During test preparation, students have to process (i.e, to select) the information their teacher considers to be important for students to learn (cf. Butler and Cartier 2004). Teachers, however, may disagree about the importance of selecting specific text contents (Alexander et al. 1994; Van Hout-Wolters 1997). For example, Van Hout-Wolters asked secondary school teachers to indicate the information they thought to be important for their students. In all four instructional texts a large variation was found both in the number and type of text fragments selected. These teachers apparently had quite different ideas about the instructional objectives to be achieved with the instructional texts. Because individual teachers may set different task demands, selecting information becomes for students a matter of assessing which task demands their teacher has set (cf. Broekkamp et al. 2004). In addition to 'complying' with instructional goals (studying for the test expected), the analysis of task requirements may also include student's analysis of personal characteristics that are relevant to the task. For instance, students may notice that a task is difficult because they have little prior knowledge about the text they are to study. Also, students may have personal interest in some of the topics they are required to learn.

Students may formulate criteria for determining the relevance of textual units. Both the definition and the application of these criteria suggest that various self-regulation processes are involved to apply the selective attention strategy in effective ways. These processes include task analysis, goal setting, strategy selection, planning, strategy outcome monitoring, strategy revision and strategy evaluation (see Broekkamp and Van HoutWolters 2007; Butler 1998a; Winne and Hadwin 1998; Zimmerman 1998). Following the model of Broekkamp and Van Hout-Wolters (2007) selecting information from a text in a learning environment emerges from an interplay between the task context (e.g., intended task demands or conditions), students' task environment (e.g., task cues), students' internal task processes (e.g., task analysis, task perceptions) and students' task dispositions (e.g., metacognitive knowledge, metacognitive skills). Task awareness runs at two levels. At the global level, selection goals and the task's instructions are represented, while at the local level, reflections about specific text parts are involved. More precisely, representations at the global task level concern major components of the task or considerations throughout the task, such as which major parts of the text to summarize in order to come up with a deeper text understanding, or to form a considerate opinion about the text. Additionally, task representations at the global level include thoughts about text or task difficulty or about time available for studying, as well. Representations at the local level are bound to specific text units, such as particular words or concepts. For example, after reading one word, the reader judges whether this specific word is important, or whether its meaning is clear before reading further.

Problems with attuning to task demands in selecting text Butler and Cartier (2004) suggest that students may experience problems in interpreting tasks because of their faulty metacognitive knowledge relative to task purpose, task structure, or task components. In our previous work, we concluded that tenth-graders experienced problems with assessing the demands of a selection task in learning from text. We asked 88 tenth-graders and their biology teachers $(n=5)$ to identify the main points in a biology text. There was a large variation in the text fragments that were selected (underlined) by both the students and their teachers. There was also a large variation in the correspondence between the students and their teachers: students clearly experienced difficulty in selecting those text fragments that 
were selected by their teacher. Questionnaire data showed that the students mentioned different reasons for selecting the main points, and more strikingly, the students who matched closely with their teacher mentioned to select in line with instruction-based criteria more often than the students who did poorly match with their teacher (Schellings and Van Hout-Wolters 1995).

In another trace study (Schellings et al. 1996), three different types of selection tasks were administered to 133 tenth-graders: in the 'linguistic' task, the students were instructed to select structural important text parts; in the 'educational' task, the students were asked to select the text parts that were considered important by a teacher; and in the 'personal' task, students were instructed to select the appealing text fragments. Each student studied three biology texts and each text was preceded by one of the three selection tasks. On average, the type of selection task did affect the number and kind of texts fragments that were selected, but only one fifth of the students selected in each single selection task the taskrelevant text fragments. It further appeared that this minority had the highest grade for biology, i.e., the course from which the experimental texts were taken. These research outcomes suggest that attuning to task demands is an ability which differs considerably among tenth-graders and is not very well developed by most of them. We explained the problems with attuning to task demands by insufficient task awareness. However, our studies were mainly product-oriented, so we are not sure what actually happened during task execution. For example, we do not know whether students keep task demands in mind while selecting information as Winne and Hadwin (1998) suggest.

Process studies in selecting text information As mentioned above, the research methods used to assess students' strategy adaption in selecting information were mainly aimed at performance data (reading times, free recalls, and test scores); and process-oriented data are limited to retrospective data (interviews and questionnaires) or trace data (underlinings; cf. Alexander and Jetton 1996; Bråten and Samuelstuen 2004; Schellings et al. 1996; Schraw et al. 1993). To assess the process of studying (or more specifically, to assess the execution of metacognitive activities) the think-aloud method is often used (see e.g., Pressley and Afflerbach 1995; Bannert and Mengelkamp 2008; Veenman 2005). Participants in thinkaloud studies perform the task while continuously reporting whatever thoughts pass through working memory (Ericsson and Simon 1984; Ericsson and Simon 1993; Veenman 2005). These verbalizations are perceived as related to the underlying thinking activities or processes. An interpreter deduces the kind of thinking activities that seem present in the verbalizations. In comparison with retrospective reports, the protocols resulting from thinkaloud methods may be less distorted by interpretations, expectations, or memory errors from the participants (Veenman 2005). However, think-aloud data seem only to provide information about activities or behaviors of a higher order level, i.e. the activities that are not (yet) automatized and hence consume room in working memory. According to Ericsson and Simon (1984), every person has direct access to the information present in working memory and the verbalization about it is accurate and without any interpretations. These authors further conclude that verbalizing about thoughts does not change the structure or course in which the cognitive activities take place. Different studies indicate that thinking aloud does not interfere with the task performance (Veenman et al. 1993; Bannert and Mengelkamp 2008).

A think-aloud study on task orientation may help to develop instruction for students, which is explicitly focused on promoting effective task representations, metacognitive task knowledge, and students' development of flexible strategies for text studying. The present process-oriented study explores task awareness during selection of text fragments. We 
analyse protocols of students who are imposed with three different selection tasks in text studying while thinking aloud. Within this study we will examine to what degree tenthgraders are aware of specific demands of the textual selection task at hand.

\section{Method}

Participants Participants were twelve 10th-graders (secondary general education; age: 15-16), who were recruited by their teacher and participated during school time. All students took a Biology course. In line with curriculum standards, the topics in the experimental texts were due to be instructed in the next grade (i.e. grade 11). The participants' ability was at an average level (with an average school grade of 6.83 for Dutch language and 6.50, for Biology; the Dutch grading scales varies from 1 (very weak) to 10 (outstanding)).

Design A within-subject design was used with three experimental conditions: each student executed three selection tasks while studying text. To avoid text effects, the student was provided with a new text in each selection task. After completion of the three selection tasks, each student had studied three texts, as well. Selection tasks and texts were balanced; the students were randomly assigned to a particular sequence of task-text combinations.

Three selection tasks in text studying The three tasks were based on the selection framework of Van Hout-Wolters (1990), which discerns three approaches in selecting main points in instructional texts: a linguistic, an educational and a cognitive-psychological approach. Students adhering to the linguistic approach select main points based on the structure of the text. The relevance of the information is determined within the text itself and the main points can be directly deduced with help of structural analyses (cf. Van Dijk and Kintsch 1983). Following the educational approach, students select information that is relevant for instruction, such as instructional goals, study guidelines, and test questions asked by their teacher (cf. Alexander and Jetton 1996). Adhering to the cognitivepsychological approach, further mentioned 'personal approach', students select information that is personally relevant, for example information important for personal goals or information that interests the student (cf. Schraw et al. 1993). Alexander and Jetton (1996) also document this kind of classifying relevant text information, but they use different terms: structural, instructional, and constructed importance. Both classifications discern three categories of importance in text that differ primarily as a result of the source that assigns importance: the author, the teacher, or the reader.

In the present study, we operationalise the third category in assigning text importance (i.e., personal or constructed importance) as interest.

Instructions for the selection tasks Three different task instructions defined the tasks of selecting linguistic, educational and personal main points, consecutively. In the linguistic instruction, the students were asked to select those text parts considered to be the most important by the author of the text. These text parts were indicated in the instruction as "main words", "main sentences" and "main parts".

In the educational instruction, the students were asked to select those text elements that were considered to be important by an imaginary biology teacher, who was especially aimed at relevant details in the texts. By describing this type of teacher, we were able to extract the linguistic main points (i.e., structural relevant text parts) from the instructional 
main points (i.e., the text elements receiving their relevance following the ideas of the teacher). In this way, textual overlap between educational and linguistic main points was avoided. Obviously, educational main points do not correspond per definition to relevant details, but many (real) teachers indeed consider these particular text parts to be important to learn (Alexander et al. 1994; Van Hout-Wolters 1990). In school, teachers frequently require children to find facts in text chapters, locate critical details in narratives, and isolate numbers in tables (cf. Guthrie and Kirsch 1987). The imaginary teacher was vividly described and by giving him a name (Mr. Ringnalda), students experienced this person as a very real person. Specifically, Mr. Ringnalda, was described as considering the elaborations of the main ideas to be important, such as specific definitions, the exact descriptions of processes, and names of substances. The information about him specifically referred to text contents (e.g., "Mr. Ringnalda considers the names of hormones very important") instead of giving general descriptions (e.g., "he prefers important details").

In the personal instruction, the students were asked to select those text fragments which the students themselves considered to be interesting. It was stressed that they should base their selection on their own point of view or that the selected text parts should arouse interest of friends.

Three texts Three texts (each about 1100 words) were chosen from a Dutch instructional method for Biology, and concerned sense organs, regulation of bodily processes, and bodily reactions, consecutively. As already mentioned, these topics were not to be discussed in grade 10 (according to the objectives in the curriculum). Because the texts were fairly difficult to read, we expected that they would stimulate the students to apply relatively more conscious text selecting activities resulting in more verbalizations (cf. Pressley and Afflerbach 1995).

Text parts were labelled to distinguish between the different kinds of main points. First, an outline of each text was made; this outline concerned a hierarchical scheme of structural importance. With help of this scheme, three levels of structural importance were discerned: the topic level, the main idea level, and detail level. The topic level is the gist of the text, which is elaborated with important information on the main idea level. All text fragments on the topic and main idea level were labelled the linguistic main points. The detail (third) level of structural importance concerns text fragments that elaborate the main ideas. In designing the educational task instructions, these text fragments were operationalised as the educational main points (see Instructions). Finally, the three texts were expanded by introductory examples or by short vivid stories to trigger the interest of the students. In this way, 'text-based' interest was aroused: interest provoked by reading attractive text parts (cf. Hidi 1990; Wade et al. 1993). Although we acknowledged that text-based interest is not automatically equivalent to students' personal interest, we labelled these particular text parts as the 'personal' main points.

Cues were placed in each text to point to the different kinds of main points. To signal linguistic main points, we inserted text structure cues, such as repetition of words and general concepts, lexical cues, such as the use of words like "important" or "major", and summary cues, such as "To summarise" or "In brief". The educational main points were cued by the instruction of the teacher Mr. Ringnalda (see Instructions). The personal main points (i.e., the text parts to raise the reader's interest) were introduced by text parts such as "Imagine" or "Read the following story".

In Table 1, a short example is presented how the text parts were differentiated. In the text presented to the students no visual marking was used, the students were presented a plain text. 
Table 1 Defining three types of main points in the introductory section of one experimental text

Text: Bodily Reactions by André Van Der Zee

Read the following story: Playing sports is healthy for heart and blood vessels. But are sports games healthy for your muscles and your bones? At least $\mathbf{4 5 0 . 0 0 0}$ women and men annually consult their physician about a sports injury ...

The nervous system reacts upon information provided by the senses. Sometimes the information is stored. More often, the body immediately reacts: muscles or glands are going to function. The muscles from the skeleton take care for posture and movements. Many parts in the brain are functioning in complex movements. These movements are complex, because many muscles must be strained and be relaxed in order to speak or write. The brain bears responsibility for the correct orchestration and execution of complex moves. To be short, the body comprises two important reactions to incoming information.

The most important topics that I will discuss concern: the storage of information in the brain and muscular actions. Additionally, I will attend to the consequences of muscular actions: correction of the muscles and the skeleton's position.

Now, I am going to describe, ... etc.

\section{Defining the different text parts in the text excerpt above:}

Linguistic text parts = Main points based on the text structure (here printed in plain text).

Signaled by the phrases: "To be short"; "The most important topics"

Educational text parts $=$ Information relevant through instruction (here printed in italics)

Cued by the instruction: "In his lessons, Mr. Ringnalda discussed the process of complex movements in great depth. He had paid a lot of attention to the exact role of the brain in orchestrating the movements through specialized nerve cells."

Personal text parts $=$ Information noteworthy for the reader (here printed in bold).

These parts are introduced in the text: "Read the following story".

note $=$ The participants were provided with the plain text: they received no visual cuing

Procedure Students were instructed to select text parts by underlining. They were asked to think aloud during task execution, including reading aloud the instruction and the text. The study was scheduled in four separate sessions (one training session and three 'task' sessions, in each 'task' session just one selection task was administered). In the training session, the think-aloud procedure was explained first. Students were told to read the text aloud and to verbalize any thoughts that arose during text reading: as soon as a thought popped into the student's head, she or he should tell about it. This way of verbalizing thoughts was practiced in two ways: first, the students had to tie a knot and second, they had to read a short exemplary text (about human behavior). During both tasks, they were stimulated to think-aloud.

In each 'task' session, the students were presented one selection task. When students underlined text parts without verbalization, the test assistant gave a short prompt stimulating the student to keep thinking aloud (e.g., "What are you thinking now?", "Keep on thinking aloud, please"). There were no "why" questions asked. By avoiding "why" questions the students did not explain their selection activities, they just put their thoughts into words. There were no time limits for each 'task' session. The 'task' sessions were audiotaped and the 36 protocols were transcribed.

Construction of a coding instrument Because coding instruments aimed at task awareness during selecting were not available, we constructed a new instrument. We defined task awareness as a conscious representation of a selection process (see Introduction), so a sign of task awareness could only be found when learners have verbalized about it. In addition, task awareness involved both processes at a global (i.e., concerning the whole task) and a 
local task level (i.e., concerning specific text parts). All verbalizations referring to possible processing activities that seemed independent from task demands were ignored (e.g., the verbalization "I don't understand this sentence, I will read it again" was not coded).

First, the protocols were segmented in passages in which only reading took place. The remaining text fragments were further segmented in thought units. The separate units were then categorized according to coding rules. These rules were established through theorising and discussing by the researchers. All verbalizations were discussed by two researchers resulting in one code for the verbalization. Afterwards, another rater, who was unfamiliar with our work, was asked to code 9 protocols (i.e., 95 units were coded within these protocols). The interrater reliability (Cohen's Kappa) reached 0.69 without an extensive period of training.

Coding categories Verbalizations signaling task awareness at the global level involved reflections on selection goals (for example: "Now this, this piece that I've just read, is again a summary of the text before, so this is important"; "Yes, other factors as well, now ... I have to search here for a factor"). Selection goals defined the number and type of text fragments the students selected. If these selection goals corresponded to the particular selection task that was instructed, the student was aware of the task demands. Verbalizations signaling task awareness at the local level involved reasons for selecting specific words, names or sentences in the text (see Table 2). These considerations were applied at the protocols, resulting in 11 categories. Most protocol segments (units) were coded in one category; some units were double coded.

At the global task level, the categories involved rereading or thoroughly processing the task instruction (see Table 2, 1a and 1b), verbalizations referring to general selection goals (2), which were subcategorised by the approach of selection they referred to $(2 \mathrm{a}, 2 \mathrm{~b}, 2 \mathrm{c}$, $2 \mathrm{~d}$ ), and verbalizations referring to the general task of studying a biology text (3). At the local level, the categories involved verbalizations showing substantial reasoning about whether a certain text part should be selected (4) and these reasons for selecting were subcategorised by the approach of selection they referred to, as well (4a, 4b, 4c). Another category at the local task level concerned labeling text parts: the verbalizations did not make clear why the particular text part was important, it was merely said that it was (5).

\section{Results}

In order to describe the results, we present three Tables. In Table 3, the overall results (i.e., the occurrences of verbalizations) are depicted, whereas Table 4 shows the number of coded verbalizations specified for each selection task (linguistic, educational, and the personal task; 12 protocols per task). In Table 5, the outcomes of a chi-square analysis are presented.

The overall results (Table 3 ) refer to the cumulative number of the coded verbalizations in all 36 protocols, the number of protocols in which the coded verbalization was shown, and the maximum occurrence of the coded verbalization found within one protocol.

Before interpreting the results, we should emphasize that verbal reports might not be complete. All a researcher can analyze is the protocol's content, and unspoken processes that do give rise to these verbalizations must be inferred. Furthermore, a reader may not be able to say everything that comes to mind, and may edit or omit thoughts that do come to mind (Magliano et al. submitted; Magliano and Graesser 1991). The think-aloud method seems preeminently suitable to tap conscious reflections (see Introduction). But any set of verbalizations still provide an approximation of what a reader (or readers) actually does (or do). In this study, task awareness is indicated by substantial reasoning about why to select. 
Table 2 The coding instrument: descriptions of the categories and examples of protocol fragments

Global task level : Verbalizations aimed at the whole task

Verbalizations about the instruction

1a. Rereading the instruction

1b. Thoroughly processing the instruction during (re-)reading
Students reread (parts of) the instruction.

Verbalizations indicate active processing, such as underlining, summarising and checking understanding of the instruction. " $<$ student reread instruction $>$ Yes, he thinks this to be important, so in the test he probably will be asking about the processes of life, hormones and substances".

Reflection on selection goals

Explicit and implicit expressions about general selection goals; any thought that concerned the question: What kind of information do I have to select? Statements are applicable to the whole task of selection.

2a. Reference to linguistic approach

2b. Reference to educational approach

2c. Reference to personal approach

2d. No (clear) reference to a selection approach

3 Other reflections at the global task level
Verbalizations refer to the structure of the text; thoughts about questions like: Which information is the gist of the text; Have I selected key words and core sentences? What does the author consider important? "I have hardly done anything in this text, only underlined the conclusions" "This is the summary, so the preceding part was not important". "eh... this is just an example, I don't think that you.. yes..eh ... when you understand this, it is enough... you don't have to mark unimportant information"

Verbalizations reflect about the teacher, or about a general authority who construct the test questions; verbalizations often include the terms such as 'must' or 'have to' "This is important, as well, because it contain names, so you probably have to know this" " <student underlines $>$ When I get his test about this, then <students laughs> I'm completely puzzled"

Verbalizations refer to personal goals, previous knowledge, and interest; thoughts about questions like: What do I know about sense organs? Do I find the text interesting? "Yes, this is interesting, but not for my friends" "So far, this stuff is not interesting"

This category concerns the remaining verbalizations, which do not reveal a particular selection approach, but they do refer to the task of selecting. "everything seems to be important, but I haven't underline anything"

The verbalizations do not refer to selection goals, but they do refer to the task at hand. For example, statement such as expressing attitudes towards the task or text, assessing text comprehension, referring to text difficulty; formulating action plans. "I don't like biology texts" "there are so many words in this text that I don't know" "I'll just read this text very fast now"

Local task level: Verbalizations directed to specific text parts

Definite reasons for selection

Clear (substantial) reasoning about whether a specific text part should be selected. All reasons could be subcategorised by one of the three approaches $(\mathrm{a}-\mathrm{c})$

4a. Reference to linguistic approach

Verbalizations refer to the linguistic function of the text part, such as summarizing, illustrating, or cueing 
Table 2 (continued)

Category Description and examples of protocolfragments

4b. Reference to educational approach

4c. Reference to personal approach

5. Labeling text parts (valuing text information) structural or lexical importance. "underline this, it's a summary" "this is not important, it's an example" "must be important, otherwise they won't repeat this" "Important...because it is said that it is important"

Verbalizations refer to the imaginary teacher, or to the test questions expected by the student. "if this question about modification is asked, then I have to underline this" "this is necessary for the test" "this relates to those cells and he will be asking about that matter, nerve cells"

Verbalizations refer to interests, personal goals, and previous knowledge of the student. "this is important, because I didn't know that" "this is important, as well, otherwise you don't know how it works"

Verbalizations concern short utterances of the student: it does not become clear why particular text parts are considered to be important, it is merely said that they are; further these verbalizations often do not indicate whether text parts are selected or they indicate rather automatic selection actions (selecting without reasoning). "this is important"; "also important"; "important again"; "hmm interesting"; "funny"

The global task level

Concerning the task instruction In 5 of the 36 protocols the instruction was reread; in one protocol the instruction was reread twice. Remarkably, the educational instruction, in which

Table 3 Occurrences of the verbalizations

\begin{tabular}{llll}
\hline Category & $\begin{array}{l}\text { Cumulative N } \\
(36 \text { protocols })\end{array}$ & $\begin{array}{l}\text { Number of } \\
\text { protocols showing }\end{array}$ & $\begin{array}{l}\text { Maximum number } \\
\text { within one protocol }\end{array}$ \\
\hline
\end{tabular}

Global task level

1a. Rereading instruction

1b. Thoroughly processing instruction

2. General reflections on selection goals (total)

a. Linguistic

b. Educational

c. Personal

d. unclear reference

3. Other reflections on task

Local task level

4. Definite reasons for selection (total)

a. linguistic

b. educational

c. personal

5. Labeling text parts

(36 protocols) protocols showing

number

\section{1} . 
Table 4 Occurrences of the verbalizations within the linguistic, educational, and personal task

Category

Task:
Occurrences of the verbalizations per task

Linguistic Educational Personal

Global task level

1a. Rereading instruction

1b. Deep processing instruction

2. General reflections selection goals (total)

a. linguistic

b. educational

c. personal

d. unclear reference

3. Other reflections on task

Local task level

4. Definite reasons for selection (total)

a. linguistic

b. educational

c. personal

5. Labeling text parts
2

1

9

2

4

0

1

4

1

2

0

6

24

$26 \quad 3$

21

16

5

0

39
16

14

1

35
21

15

8

1

3

12

5

1

6

27

very detailed information was presented, did not result in extensive rereading (4 occurrences). Besides, reading the instruction was rarely accompanied by activities that support deep processing of it (such as paraphrasing, summarizing, etc.); nine occurrences of thoroughly processing were found in 6 protocols. The educational instruction (7) initiated

Table $5 X^{2}$-test: Task $\times$ Coded verbalization

\begin{tabular}{|c|c|c|c|c|c|}
\hline & \multicolumn{2}{|c|}{ Task $\times$ Code $^{\mathrm{a}}-$ match } & \multicolumn{2}{|c|}{ Task $\times$ Code $^{\mathrm{a}}-$ mismatch } & \multirow[t]{2}{*}{ Total } \\
\hline & Observed & (expected) & Observed & (expected) & \\
\hline \multicolumn{6}{|l|}{ Global task level: } \\
\hline Linguistic task & 1 & $(1.95)$ & 2 & $(1.05)$ & 3 \\
\hline Educational task & 0 & $(0.65)$ & 1 & $(0.35)$ & 1 \\
\hline Personal task & 12 & $(10.40)$ & 4 & $(5.60)$ & 16 \\
\hline Total & 13 & & 7 & & $\begin{array}{l}20 \\
X^{2}=3.88\end{array}$ \\
\hline \multicolumn{6}{|l|}{ Local task level: } \\
\hline Linguistic task & 21 & $(14.81)$ & 5 & $(10.75)$ & 26 \\
\hline Educational task & 14 & $(17.65)$ & 17 & $(13.35)$ & 31 \\
\hline Personal task & 6 & $(8.54)$ & 9 & $(6.46)$ & 15 \\
\hline Total & 41 & & 31 & & $\begin{array}{l}72 \\
X^{2}=9.17^{*}\end{array}$ \\
\hline \multicolumn{6}{|c|}{${ }^{\mathrm{a}}$ verbalization coded } \\
\hline
\end{tabular}


more occurrences of deep processing than the linguistic (1) and personal instruction (1), probably of its detailed information. However, the frequencies remained small.

Reflections about selection goals In all, 34 verbalizations about selection goals were found. Of these 34 verbalizations, 14 fragments did not clearly refer to one of the three selection approaches (see Table 3 ). Of the 20 remaining reflections, most verbalizations concerned references to the personal approach (12 verbalizations in 4 protocols). Reflections on the educational or linguistic approach appeared less frequent, respectively 5 verbalizations in 3 protocols, and 3 verbalizations in 3 protocols.

As we were only interested in the match between the task instruction and the coded verbalization (i.e, the reflection about a selection goal at the global task level), a chi-square test was performed with the three tasks and match or mismatch verbalization. There was no significant relation between task and varbalization at the global level (see Table 5).

Overall, reflections about selection goals were not often found and there was no dependence between the task instruction and the reflection about the selection goal at the global task level.

Other kind of reflections about the task Other types of reflections such as assessing text difficulty or process planning were more frequent: 66 occurrences in 30 protocols (see Table 3). The students frequently verbalized about the task as a whole (for example, " $a$ difficult text"; "Now, I will read all the summaries"; "I have to say I didn't understand a thing of this text'). So, it seemed that verbalizing about 'text studying' is more common than verbalizing about the specific task demands (i.e., here verbalizing about the selection task).

Conclusion The think-aloud data showed relatively few signs of task awareness at a global task level: students did not thoroughly process the instructions of the tasks, nor did they verbalize much about selection goals; most verbalizations about the task concerned aspects of the student's reading (such as comprehension difficulties), which might also indicate that these readers (10th graders) do not commonly read (or search) for relevant information in short texts.

The local task level

Definite reasons for selection The total number of definite reasons mentioned (selecting particular text parts with substantial reasoning) was 72 . In all three tasks (see Table 3), the reasons mentioned most were linguistic (45). Furthermore, as shown in Table 4, these linguistic reasons ("this is a summary"; yeah, this is a summary, so this is important, as well") were expressed in the linguistic task (21), in the educational task (16), and in the personal task (8). Educational and personal reasons were mainly expressed in the corresponding tasks: educational reasons ("yes this includes those cells, and he is all gonna to .. nerve cells", "yeah, I believe that you ought to know these processes") most in the educational task (14), and the personal reasons ("that's a funny example") most in the personal task (6). Consequently, these results suggested that type of task have affected the selection reasons. However, linguistic selection reasons were uttered most, regardless of the selection task.

Again, a chi-square test was performed with the three tasks and match or mismatch verbalization. There was a significant relation between task and verbalization at the local task level $\left(X^{2}(\mathrm{df}=2)=9.17 p<.025\right)$, implying that the linguistic task resulted in relatively more matching verbalizations, compared to the other two tasks. 
Labeling text parts The protocols showed many verbalizations that merely valued text information without referring to one of the three selection approaches (for example: "this is important"). In all, 27 protocols showed a total of 101 of these verbalizations (see Table 3). In one protocol, even 20 verbalizations of this type were found. Once again, these verbalizations did not make clear why the student considered the text information to be important.

Conclusion At the local task level, more signs of task awareness (72) were found than at the global task level (34). At the local level, the task instruction affected the selection reasons, the linguistic task seem to result in more matching verbalizations than the other two tasks. However, most verbalizations (at both levels) did not refer to selection activities (101 and 66 verbalizations, respectively).

\section{Discussion}

This study examined students' signaling task awareness during the selection of main points, using verbal protocol data. More precisely, we examined to what degree tenth-graders were aware of specific demands from three different selection tasks. In the linguistic task, the students should select structural important text parts, in the educational task the students were instructed to select text parts that were considered to be important by a teacher, and interesting text parts were to be selected in the personal relevance task. In the think-aloud protocols, signs of task awareness did appear, mainly at the specific task level. Task awareness was conceived as conscious task representations both at a global task level (concerning the task as a whole) and at a local task level (reasoning about specific text parts). Few signs of task awareness were found at the global task level. Students occasionally reflected on goals for selecting. Besides, the three different instructions were hardly reread nor thoroughly processed. More signs of task awareness were observed at the local task level: students verbalized reasons for selecting particular text parts, and these reasons statistically matched with the selection task instructed, especially the linguistic task instruction seem to affect the selection reasons verbalized. But overall, the number of verbalizations concerning task awareness (at both task levels) remained rather low. The outcome that irrespective of the task, most reasons for selecting text parts were linguistic ones, suggests that students use default selection strategies corresponding with the linguistic approach of selecting. In our previous product-oriented study, too, we concluded that students did not ignore the linguistic variables while selecting text fragments (Schellings et al. 1996). Irrespective of the task, students seem to select the text parts that are positioned high in the text structure to build a macrostructure of the text (cf. Kintsch 1998). As the questionnaire data showed in our prior study, the educational reasons were mainly verbalized in the educational task and the personal reasons were verbalized most in the personal task. Our overall conclusion is that this think-loud study confirmed our productoriented studies: tenth-graders experience difficulties in selecting text parts according to specific instructions.

It is noteworthy that we found only few signs of task awareness. As mentioned in the Introduction, self-regulated, strategic or flexible learning requires attuning to task demands, and in turn, attuning to task demands obviously requires task awareness. In fact, learners often do not have the educational objectives or personal learning goals clear in mind. A clear notion of what the objectives and/or task demands really are might significantly differentiate between the learners with successful achievements and learners with less 
successful achievements. For example, we observed that the adaptive students, that is, the students who selected text fragments according to different tasks, were the students with the highest grades (Schellings et al. 1996).

Task awareness is an important phenomenon and the appearances (and nonappearances) of signs of task awareness should be studied in depth. The fact that we found few indications of task awareness can be explained by the stage of metacognitive development of the population studied. Many authors stress the role of developmental processes in metacognitive ability (cf. Veenman et al. 2006). Most likely, metacognitive skills already develop during early-school years at a very basic level, but become more sophisticated and academically oriented whenever formal educational requires the explicit utilization of a metacognitive repertoire. It seems, then, that the population we studied was at a stage in which task awareness was not fully developed. We think that the participants had at least some awareness of the task.

Nonetheless alternative explanations of the findings are possible, which concentrate on the research method used. The think-aloud method seems pre-eminently suitable to tap conscious reflections about task awareness (see Introduction), while selection activities might occur rather unconsciously or automatically. Additionally, the coding instrument leaves much room for dialogue: all verbalizations were discussed by the two researchers to come up with one code. The interrater reliability reached without training seemed to be modest, yet values between .40 and .75 could be considered fair to good agreement beyond chance (e.g., Fleiss et al. 2003, p.604). However, the interrater reliability of 0.69 within this study indicates that at times the verbalizations were not clearly pointing to the precise reasons for selecting and interpretation was needed.

Furthermore, an intriguing question is why the coding category "labeling text parts" is most prevalent among the students. Within this category, the verbalizations all seemed to judge the particular text parts as important, funny, etcetera, without specifying clear reasons for selection. These verbalizations often were short utterances of the participant through which it did not become evident why particular text parts were considered to be important or funny, it was merely said that they were. Precisely this type of verbalizations raises questions about using the think-aloud method in examining task awareness. In this study, task awareness is indicated by substantial reasoning about why to select. But learners may still be aware of the selection task when the reasoning is not provided. For example, once a learner has constructed a representation of the task, new text information might be judged with the help of this constructed representation without 'extensive' reasoning. In this way the verbalizations only include a label (e.g., "this is important"). It might be rather laborious to add specific selection reasons each time a text fragment is selected. On the other hand, it is also possible that judging information at the local task level is an automatic process, rendering verbalizations difficult, if not impossible (cf. Ericsson and Simon 1984). These results raise the issue about the methodological soundness of the think-aloud method in examining task awareness. We need to search for methods that unravel the unconscious processes and to overcome the methodological limits. For example, also eye-tracking would not help to get insight into why learners attend to text elements at the expense of other text elements; we could only observe that it happens.

Our interests concern students' decisions at the selection level in studying texts. In fact, we were especially interested in their explicit reasoning. Following Pressley and Afflerbach (1995), who recommended routines most suited for protocol analysis, we avoided asking why-questions. However, examining the selection level, it may be inevitable to ask the students "why do you select this?", and "why do you find this funny?". In other words, we have to find a way to stimulate the students to explain their selection activities in order to be 
able to interpret whether students are aware of the task demands at hand. However an adverse effect of this routine might be that by stimulating the students to explain their activities (self-explanation paradigm, cf. McNamara 2004; or retrospective interviewing and cognitive probing; cf. Karabenick et al. 2007), the students become more aware of the task than they would be without the stimulation.

Most think-aloud studies are aimed at text processing activities, learning strategies and self-regulation. The think-aloud protocols are fragmented and coded with broader codingcategories (i.e., "constructing the main idea" than the specific coding categories used in this study (cf. Pressley and Afflerbach 1995). The present study makes clear that examining task awareness requires refined protocol analysis (recall that many verbalizations within this study were not coded) and even some new ways of thinking aloud (thinking-aloud combined with "why"-questions). Further research should give insight into the question how to examine instances of task awareness, for example, by comparing different methods of thinking aloud, by searching for retrospective methods, by triangulating process data with product data, and by combining measurement methods (Veenman et al. 2006).

Our work is congruent with the notion of many teachers that readers (at least 10th graders) do not seem to search for relevant information during reading texts. This deficit deeply questions school practices about text reading and comprehension. This study, developmental in nature, is a first step in constructing instructional methods to remedy the lack of awareness, and we will conclude with some instructional implications. First of all, we suggest that teachers provide their students with sufficient information about the intended task demands and ensure that this information is aligned with the tasks they ultimately set upon their students. Second, we suggest that teachers ensure that the task demands they formulate are convincing and compelling enough. As long as students have latitude to be successful with routine selection strategies, it is possible they won't experiment with new types of selection strategies, or engage in adapting their routine ones. Third, we suggest that teachers vary the types of study tasks they give to their students. For instance, tasks that require memorization of information could be alternated with tasks that require deep comprehension. Similarly, studying history texts from an economic perspective could be alternated with studying history texts from a cultural perspective. Students may think that relevant information in texts exclusively refers to text-based importance. To become aware of task demands, students have to learn that different criteria exist for determining relevance: author-based, reader-based and instruction-based criteria. With help of these criteria, teachers should explain the occurrence of overlap and frictions between the relevance of different text fragments both within their particular domain and within the different study tasks; the teaching of selecting relevant information should be integrated in teaching the topics within the specific instructional domains and in the specific task situations. Fourth, teachers should give metacognitive support to their students, for instance, by asking them to judge the importance of text units and to explain their judgments (cf. Butler 1998b). By doing this, teachers not only stimulate strategy adaptation processes, but also inform themselves whether students' ways of studying match their own intentions regarding the study task.

To conclude, signs of task awareness (instances of a conscious task representation) did appear in this particular think-aloud study (especially at the specific task level): the participants had at least some awareness of the task demands. In addition to the finding that few protocols did show conscious and active representation of selection goals at the global task level, almost all protocols showed some awareness of the task at the local task level. A considerable number of definite selection reasons was found, which to a certain extent, appeared to be influenced by the task. However, on the basis of both this process-oriented 
study and our previous product-oriented studies, we conclude that tenth-graders are not much aware of the task. Even in the educational task, with its specific and very detailed demands, signs of awareness were rarely found. In school settings, students should be able to attune to different task demands and regulate their learning activities accordingly. Attuning to task demands requires in the first place that the student has a clear notion about what the task demands consist of. Students need to be instructed in their abilities to assess the task demands in their educational environment.

Open Access This article is distributed under the terms of the Creative Commons Attribution Noncommercial License which permits any noncommercial use, distribution, and reproduction in any medium, provided the original author(s) and source are credited.

\section{References}

Alexander, P. A., \& Jetton, T. L. (1996). The role of importance and interest in processing of text. Educational Psychology Review, 8, 89-121.

Alexander, P. A., \& Jetton, T. L. (2000). Learning from text: A multidimensional and developmental perspective. In R. Barr (Ed.), Handbook of reading research Vol. 3 (pp. 285-310). Hillsdale: Erlbaum.

Alexander, P. A., Jetton, T. L., Kulikowich, J. M., \& Woehler, C. A. (1994). Contrasting instructional and structural importance: the seductive effect of teacher questions. Journal of Reading Behaviour. A journal of literacy, 26, 19-47.

Anderson, R. C. (1982). Allocation of attention during reading. In A. Flammer \& W. Kintsch (Eds.), Discourse processing (pp. 292-305). New York: North Holland.

Anderson, T. H., \& Armbruster, B. B. (1984). Studying. In P. D. Pearson (Ed.), Handbook of reading research (pp. 657-679). New York: Longman.

Bannert, M., \& Mengelkamp, C. (2008). Assessment of metacognitive skills by means of instruction to think aloud and reflect when prompted. Does the verbalization method affect the learning? Metacognition and Learning, 3, 39-58.

Boekaerts, M., \& Corno, L. (2005). Self-regulation in the classroom: a perspective on assessment and intervention. Applied Psychology: An international Review, 54, 199-231.

Bråten, I., \& Samuelstuen, M. S. (2004). Does the influence of reading purpose on reports of strategic text processing depend on students' topic knowledge? Journal of Educational Psychology, 96, 324-336.

Broekkamp, H., \& Van Hout-Wolters, B. H. A. M. (2007). Students adaptation of study strategies when preparing for classroom tests. Educational Psychology Review, 19, 401-228.

Broekkamp, H., Van Hout-Wolters, B. H. A. M., Van den Bergh, H., \& Rijlaarsdam, G. (2004). Teachers' task demands, students test expectations and actual test content. The British Journal of Educational Psychology, 74, 205-218.

Butler, D. L. (1998a). Metacognition and learning disabilities. In B. Y. L. Wong (Ed.), Learning about learning disabilities (2nd ed., pp. 277-307). San Diego: Academic.

Butler, D. L. (1998b). The strategic content learning approach to promoting selfregulated learning: a report of three studies. Journal of Educational Psychology, 90, 682-697.

Butler, D. L., \& Cartier, S. C. (2004). Promoting effective task interpretation as an important work habit: a key to successful teaching and learning. Teachers College Record, 106, 1729-1758.

Butler, D. L., \& Winne, P. H. (1995). Feedback and self-regulated learning: a theoretical synthesis. Review of Educational Research, 65, 245-281.

Cerdan, R., \& Vidal-Abarca, E. (2008). The effects of tasks on integrating information from multiple documents. Journal of Educational Psychology, 100, 209-222.

De Corte, E. (1996). Instructional psychology: Overview. In E. De Corte \& F. E. Weinert (Eds.), International encyclopedia of developmental and instructional psychology (pp. 33-43). Oxford (England): Elsevier.

Ericsson, K. A., \& Simon, H. A. (1984). Protocol analysis: Verbal reports as data. Cambridge: The MIT Press.

Ericsson, K. A., \& Simon, H. A. (1993). Protocol analysis: Verbal reports as data. Cambridge: MIT Press. Fleiss, J. L., Levin, B. A., \& Paik, M. C. (2003). Statistical methods for rates and proportions (3rd ed.). Hoboken: Wiley. 
Guthrie, J. T., \& Kirsch, I. S. (1987). Distinctions between reading comprehension and locating information in text. Journal of Educational Psychology, 79, 220-227.

Hidi, S. (1990). Interest and its contribution as a mental resource for learning. Review of Educational Research, 60, 549-571.

Hidi, S. E. (1995). A reexamination of the role of attention in learning from text. Educational Psychology Review, 7, 323-350.

Hodgson, V. (1997). Lectures and the experience of relevance. In F. Marton, D. Hounsell, \& N. Entwistle (Eds.), The experience of learning. Implications for teaching and studying in higher education (2nd ed., pp. 159-171). Edinburgh: Scottish Academic.

Karabenick, S. A., Woolley, M. E., Friedel, J. M., Ammon, B. V., Blazevski, J., Bonney, C. R., et al. (2007). Cognitive processing of self-report items in educational research: do they think what we mean? Educational Psychologist, 42(3), 139-151.

Kintsch, W. (1998). Comprehension: A paradigm for cognition. New York: Cambridge University Press.

Magliano, J. P., \& Graesser, A. C. (1991). A three-pronged method for studying inference generation in literary text. Poetics, 20, 193-232.

Magliano, J. P., Millis, K. K., The RSAT Development Team, Levinstein, I., \& Boonthum, C. (submitted). Assessing comprehension during reading with the Reading Strategy Assessment Tool (RSAT).

Mayer, R. E. (1992). Cognition and instruction: their historic meeting within educational psychology. Journal of Educational Psychology, 84, 405-412.

McNamara, D. S. (2004). SERT: self-explanation reading training. Discourse Processes, 38, 1-30.

Meijer, J., Veenman, M. V. J., \& van Hout-Wolters, B. H. A. M. (2006). Metacognitive activities in text studying and problem solving: development of a taxonomy. Educational Research and Evaluation, 12, 209-237.

Pintrich, P. R., Wolters, C. A., \& Baxter, G. P. (2000). Assessing metacognition and self-regulation. In G. Schraw \& Impara (Eds.), Issues in the measurement of metacognition (pp. 43-98). Lincoln: Buros Institute of Mental Measurements.

Pressley, M., \& Afflerbach, P. (1995). Verbal protocols of reading: The nature of constructively responsive reading. Hillsdale: Erlbaum.

Reynolds, R. E. (1992). Selective attention and prose learning: theoretical and empirical research. Educational Psychology Review, 4, 345-391.

Schellings, G. L. M., \& Van Hout-Wolters, B. H. A. M. (1995). Main points in an instructional text, as identified by students and by their teachers. Reading Research Quarterly, 30, 742-756.

Schellings, G. L. M., Van Hout-Wolters, B. H. A. M., \& Vermunt, J. D. (1996). Individual differences in adapting to three different tasks of selecting information from texts. Contemporary Educational Psychology, 21, 423-446.

Schraw, G., \& Moshman, D. (1995). Metacognitive theories. Educational Psychology Review, 7, 351-371.

Schraw, G., Wade, S. E., \& Kardash, C. A. M. (1993). Interactive effects of text-based and task-based importance on learning from text. Journal of Educational Psychology, 85, 652-661.

Schraw, G., Flowerday, T., \& Lehman, S. (2001). Increasing situational interest in the classroom. Educational Psychology Review, 13, 211-224.

Van Dijk, T. A., \& Kintsch, W. (1983). Strategies of discourse comprehension. New York: Academic.

Van Hout-Wolters, B. H. A. M. (1990). Selecting and cueing key phrases in instructional texts. In H. Mandl, E. de Corte, S. N. Bennet, \& H. F. Friedrich (Eds.), Learning and instruction - European research in an international context. Volume 22 (pp. 181-198). Oxford: Pergamon Press.

Van Hout-Wolters, B. H. A. M. (1997). Teachers' selection of key phrases in instructional texts. School Field, $6,51-62$.

Veenman, M. V. J. (2005). The assessment of metacognitive skills: What can be learned from multimethod designs? In C. Artelt \& B. Moschner (Eds.), Lernstrategien und Metakognition: Implikationen für Forschung und Praxis (pp. 75-97). Berlin: Waxmann.

Veenman, M. V. J., Elshout, J. J., \& Groen, M. G. M. (1993). Thinking aloud: does it affect regulatory processes in learning? Tijdschrift voor Onderwijsresearch, 18, 322-330.

Veenman, M. V. J., Van Hout-Wolters, B. H. A. M., \& Afflerbach, P. (2006). Metacognition and learning: conceptual and methodological considerations. Metacognition and Learning, 1, 3-15.

Wade, S. E., Schraw, G., Buxton, W. M., \& Hayes, M. T. (1993). Seduction of the strategic reader: effects of interest on strategies and recall. Reading Research Quarterly, 28, 93-114.

Walraven, A. (2008). Becoming a critical websearcher: Effects of instruction to foster transfer. Unpublished doctoral thesis. Open University, Heerlen, the Netherlands.

Winne, P. H., \& Hadwin, A. F. (1998). Studying as self-regulated learning. In D. J. Hacker, J. Dunlosky, \& A. C. Graesser (Eds.), Metacognition in educational theory and practice (pp. 277-304). Mahwah: Erlbaum.

Zimmerman, B. J. (1998). Academic studying and the development of personal skill: a self-regulated perspective. Educational Psychologist, 33, 73-86. 